\title{
Properties of a novel silver sintering die attach material for high temperature - high lifetime applications
}

\author{
S. Kraft ${ }^{1}$, S. Zischler ${ }^{1}$, N. Tham ${ }^{1}$, A. Schletz ${ }^{1}$ \\ ${ }_{1}^{1}$ Fraunhofer Institute for Integrated Systems and Device Technology IISB, Nuremberg, Germany, \\ silke.kraft@iisb.fraunhofer.de
}

\begin{abstract}
:
Silver sintering technology has proven to be a high reliable alternative for solder die attaches as well as wire bonding. Previous work at Fraunhofer IISB showed as well a rise in passive temperature cycling capability as in active temperature cycling lifetime with power electronic test modules compared to soldered and wire bonded samples. Since it is a new die attach technology, the material's properties are still not yet well know. In this work, the Young's modulus will be investigated for two different silver sinter pastes depending on mounting parameters and proceeding material fatigue during passive temperature cycling.
\end{abstract}

Key words: silver sintering, low temperature joining technique LTJT, nanoindentation, passive temperature cycling, Young's modulus.

\section{Introduction}

The use of new semiconductor materials such as $\mathrm{SiC}$ and the need for higher system integration levels demand high temperature die attach solutions at temperature ranges above those of commercial solder or conductive adhesives. For this purpose silver sintering is one promising solution and has already developed to a ready for the market-technology that has been established as a serial product in power electronics and LED production during the last years. Previous power cycling tests at Fraunhofer IISB from $+45{ }^{\circ} \mathrm{C}$ to $+175{ }^{\circ} \mathrm{C}$ with a cycling time of 30 seconds showed a 17 times higher lifetime of silver sintered power electronic test modules compared to SAC soldered and wire bonded samples [1]. Still little is known about the material's properties which are essential for lifetime prediction calculations as well as the changes of these properties with proceeding ageing and thermal fatigue.

\section{Silver Sinter Technology}

The silver sintering technology, also called low temperature joining technique (LTJT), was introduced in 1987 by Schwarzbauer and Kuhnert [2][3]. The idea of silver sintering is to benefit from the high melting temperature of silver with $961^{\circ} \mathrm{C}$ by operating samples at a higher temperature than the melting temperature of commercial eutectic $\mathrm{SnAgCu}$ solder, which is at about $227^{\circ} \mathrm{C}$.
The silver sinter paste consists of micro or nano scaled silver particles surrounded by an encapsulation material, a solvent as well as some additives, e.g. binder [4]. Comparable with solder pastes, the sinter paste is applied to the sample by screen or stencil printing or by dispensing. Sintering takes place under enhanced temperatures between $200{ }^{\circ} \mathrm{C}$ and $300{ }^{\circ} \mathrm{C}$. Depending on the size of the semiconductor device, additional pressure up to $30 \mathrm{MPa}$ or $40 \mathrm{MPa}$ may be applied to the sample during sintering. There are also approaches with sintering pastes based on other, less expensive materials then silver, e.g. copper [5].

During the last years, a lot of work has been published, mainly on the mounting parameters of the sinter pastes and its reliability. Shear tests have shown an average strength of almost $30 \mathrm{MPa}$ for pressureless sintered samples [6], whereat pressure assisted sintered samples show a higher shear strength than pressureless sintered ones [7]. A direct comparison between Sn96,5Ag3Cu0,5 solder and the sinter interconnection by passive temperature cycling tests revealed from $-55^{\circ} \mathrm{C}$ to $175^{\circ} \mathrm{C}$ revealed a statistic lifetime of 50.8 cycles for the solder and of 646 cycles of the sinter layer until $20 \%$ of delamination of the connected area [8]. Results in active temperature cycling with silver sintered samples have been constantly improved from 66,750 cycles at temperatures of $40^{\circ} \mathrm{C}$ to $170{ }^{\circ} \mathrm{C}$ with a cycling time of about two minutes 
published in 2006 by Amro et al. [9] up to 3 million cycles from $80^{\circ} \mathrm{C}$ to $150{ }^{\circ} \mathrm{C}$ with a cycling time of three seconds published by Scheuermann in 2012 [10]. Guth et al. found an 30-60 fold increase of the power cycling capability for silver sintered as well as diffusion bonded samples compared to state of the art modules [11], also in 2012.

Although there are a lot of results concerning the reliability, the material's properties depending on mounting parameters and their changes with a progress of ageing need further research. Also it is yet not known, if the sinter process progresses during passive temperature cycling. For this reasons nanoindentation measurements have been carried out on passive temperature cycled samples, which have been mounted at different sinter pressures.

\section{Sample Preparation}

A microscale silver sinter paste "LTS 174" by Heraeus and a nanoscale paste "nanoTach, kseries" by NBE Tech, LCC are investigated in this work. Both have shown a high active temperature cycling capability compared to solder or adhesive. Test specimen with three different types of squared silicon devices with a thickness between $120 \mu \mathrm{m}$ and $310 \mu \mathrm{m}$ and a length of $7.8 \mathrm{~mm}$ to $10.4 \mathrm{~mm}$ are mounted on $1 \mathrm{~mm}$ thick silver coated copper substrate by silver sintering. The three silicon devices will be refered to as chip A for SKCD61C170I by Semikron, chip B for SKCD81C12014F also by Semikron and chip C for SIGC109T120R3L by
Infineon in this text. All parameters of the test matrix with 120 samples are given in Tab. 1 .

Tab. 1: Parameters for samples setup

\begin{tabular}{|c|c|}
\hline $\begin{array}{c}\text { Sinter } \\
\text { temperature T / } \\
{ }^{\circ} \mathrm{C}\end{array}$ & 280 \\
\hline $\begin{array}{c}\text { Sinter pressure } \\
\mathrm{p} / \mathrm{MPa}\end{array}$ & $1 ; 5 ; 10 ; 15 ; 20$ \\
\hline Sinter time t/s & 120 \\
\hline Sinter pastes & nanoTach (NBE), \\
& LTS 174 (Heraeus) \\
\hline $\begin{array}{c}\text { Chip geometries } \\
/ \mathrm{mm}^{3}\end{array}$ & A: $7.8 \times 7.8 \times 0.31 \mathrm{~mm}^{3}$ \\
& C: $10.47 \times 10.44 \times 0.12 \mathrm{~mm}^{3}$ \\
\hline
\end{tabular}

The sintering process is done in an electric press at several sinter pressures between 1 and $20 \mathrm{MPa}$ for $120 \mathrm{~s}$ and at temperatures as low as $280{ }^{\circ} \mathrm{C}$. During sintering, the particles interconnect with each other as well as with the semiconductor device and the copper substrate. The sinter process does not need any flux as it is the case for solder pastes, so the modules don't have to be cleaned from the flux residues after mounting.

After sintering, the density of the sinter layer was determined by measuring the volume with the help of a surface profilometer uscan by Nanofocus as well as the weight of the paste.

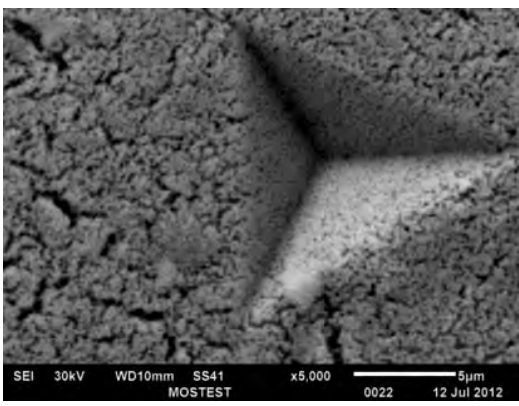

a)

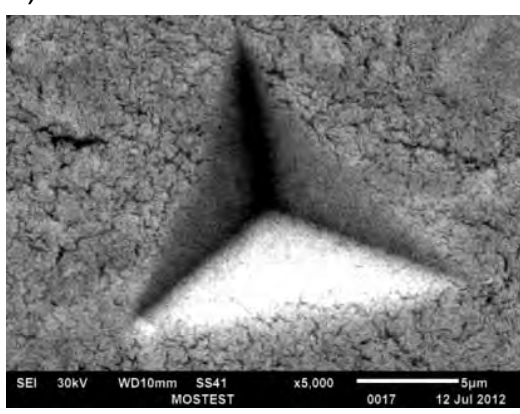

d)

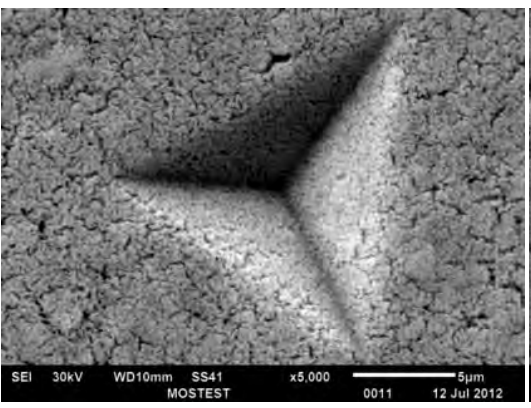

b)

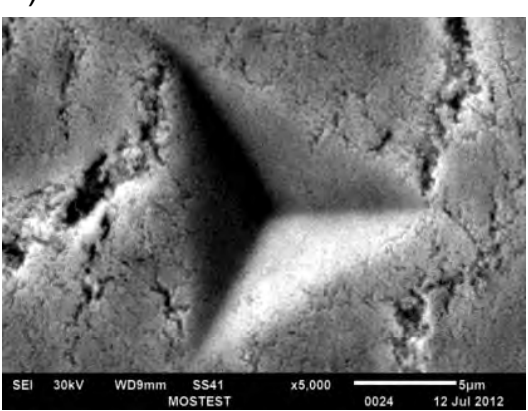

e)

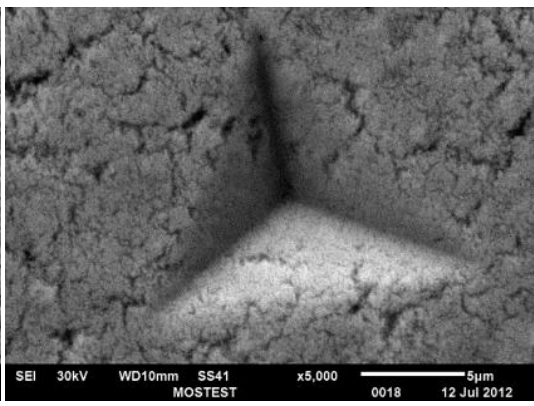

C)

Fig. 1. SEM pictures of indents in nano scale silver sinter paste nanoTach by NBE, sintering with a pressure of a) $1 \mathrm{MPa}$, b) $5 \mathrm{MPa}$, c) $10 \mathrm{MPa}$, d) $15 \mathrm{MPa}$ und e) $20 \mathrm{MPa}$. 
Additionally, samples without any semiconductor device have been mounted to proof the values of Young's modulus without thermal cycling. The indents in these samples as well as the structure of the sinter material for different sinter pressures and for both sinter pastes are shown in Fig. 1 and Fig. 2.

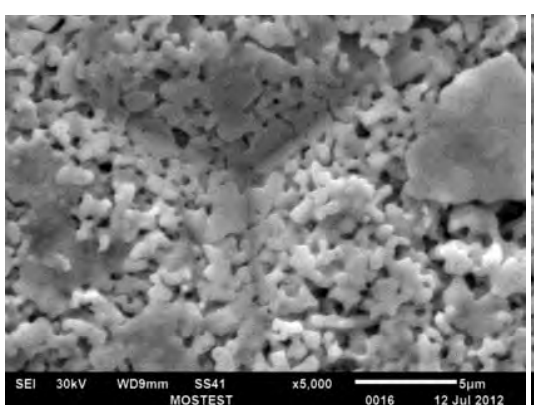

a)

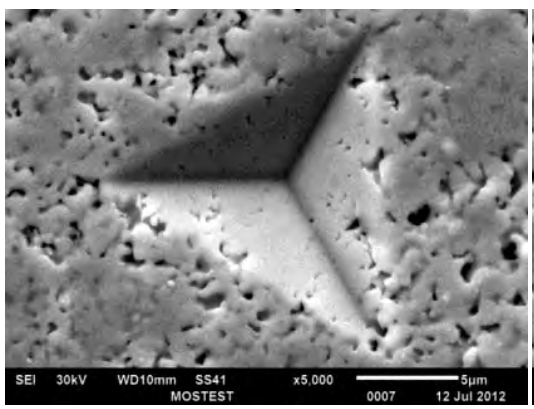

d)

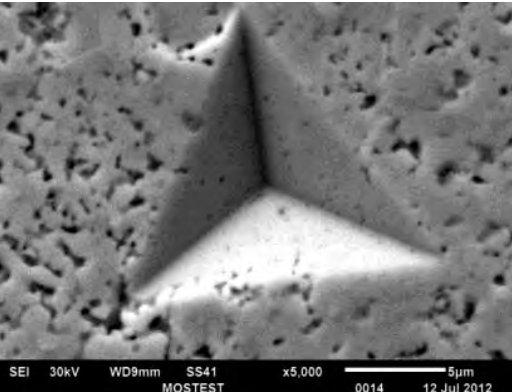

b)

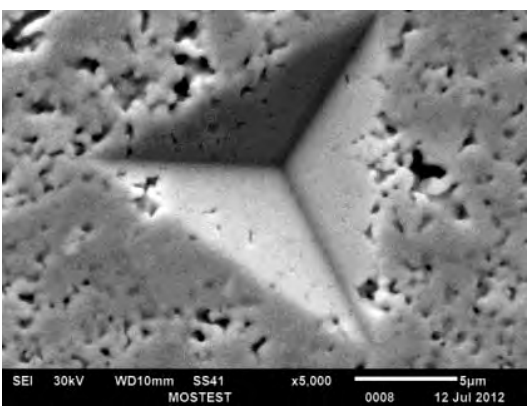

e)

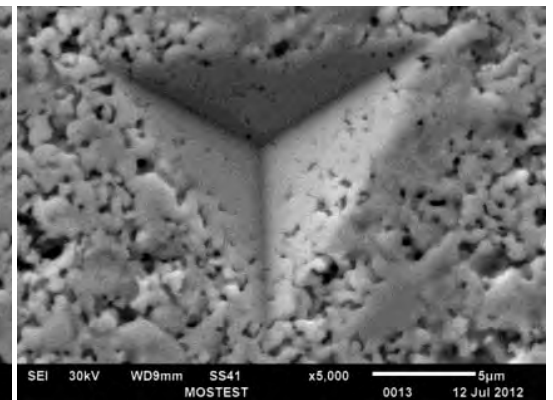

c)

Fig. 2. SEM pictures of indents in micro scale silver sinter paste LTS 174 by Heraeus, sintering for $120 \mathrm{~s}$ with a sinter pressure of a) $1 \mathrm{MPa}$. b) $5 \mathrm{MPa}$. c) $10 \mathrm{MPa}$. d) $15 \mathrm{MPa}$ und e) $20 \mathrm{MPa}$.

\section{Passive Temperature Cycling}

1000 passive temperature cycles from $-5{ }^{\circ} \mathrm{C}$ to $+175^{\circ} \mathrm{C}$ for $30 \mathrm{~min}$ respectively are carried out on the samples to reach several stages of thermomechanical ageing. The tests were run in a two chamber oven with a dwell time of 30 minutes in each chamber. The progress of delamination of the sintered layer was evaluated by scanning acoustic microscopy in periodic time intervals, as shown in Fig. 3.

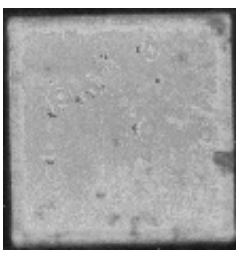

0 cycles

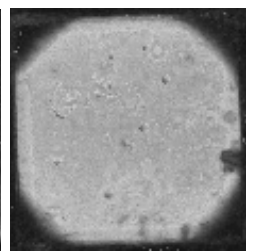

150 cycles

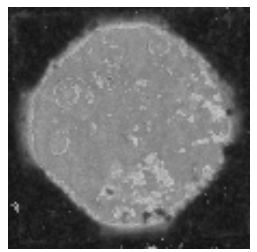

1000 cycles
Fig. 3. Progress in delamination, investigated by scanning acoustic microscopy for the nanoTach paste sintered at $15 \mathrm{MPa}$ for $120 \mathrm{~s}$ at $280^{\circ} \mathrm{C}$, chip $\mathrm{A}$.

\section{Nanoindentation}

For each of the stages in thermal cycling measurements of Young's modulus are carried out on a nanoindentation system G200 by Agilent at room temperature. A diamond
Bercovich indenter tip was used for indentation. For the measurements, the samples were embedded, grinded and polished after passive temperature cycling, and the indents were done on the cross section of the sample.

The nanoindentation system traces the load on the sample against the displacement of the indenter into the sample. The reduced elastic modulus $E_{r}$ was gained by the gradient of the unloading curve of load versus displacement, which is the stiffness of the material [12]:

$$
S=\frac{d P}{d h}=\frac{2}{\sqrt{\pi}} E_{r} \sqrt{A_{\text {projected }}}
$$

At this $P$ is the load on the sample, $h$ is the indentation depth and $A_{\text {projected }}$ is the projected area of the indenter tip on the surface of the sample. Total Young's modulus can be explained as the modulus of the sample and the modulus of the indenter tip as followed [12]:

$$
\frac{1}{E_{r}}=\frac{\left(1-v^{2}\right)}{E}+\frac{\left(1-v_{i}^{2}\right)}{E_{i}}
$$

Here $E_{i}$ is the elastic modulus of the indenter tip and $v$ the Poisson's ratio. For the silver material 
a Poisson's ratio of 0.3 was assumed. An example of the gained load over displacement curves is given in Fig. 4 .

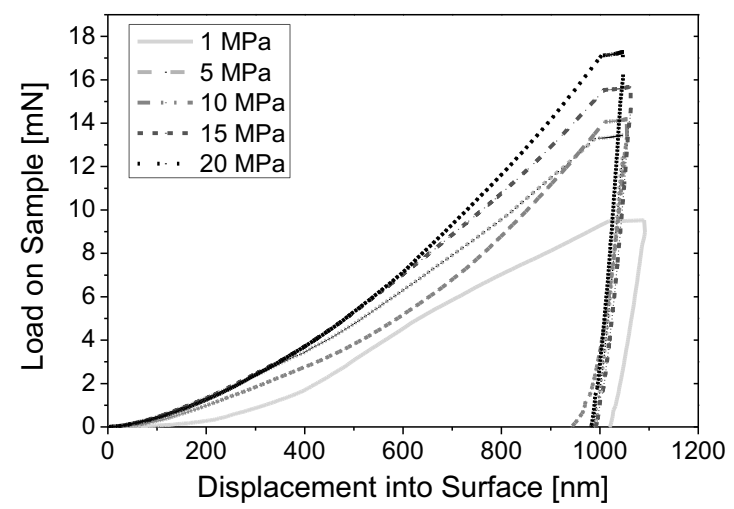

Fig. 4. Force versus displacement after 500 cycles from $-5{ }^{\circ} \mathrm{C}$ to $+174{ }^{\circ} \mathrm{C}$ for paste LTS 174 , chip C

Measurements of the Young's modulus showed a large variation of the curves for one sample. This is due to the inhomogeneous porosity of the sintered layers. Therefore 10 indents have been run on one sample and the average was built. Also creep behavior can be seen in the curves.

The measurements then were compared to the progress of material fatigue in terms of delaminated area of the sinter layer. The delamination progress of the sintered layers is correlated to the Young's modulus.

\section{Results and discussion}

The densities of the silver sintered samples are given in Fig. 5. The sinter behavior of both sinter pastes is similar, and with both pastes almost the density of pure silver with $10.49 \mathrm{~g} / \mathrm{cm}^{3}$ can be reached at higher sinter pressures.

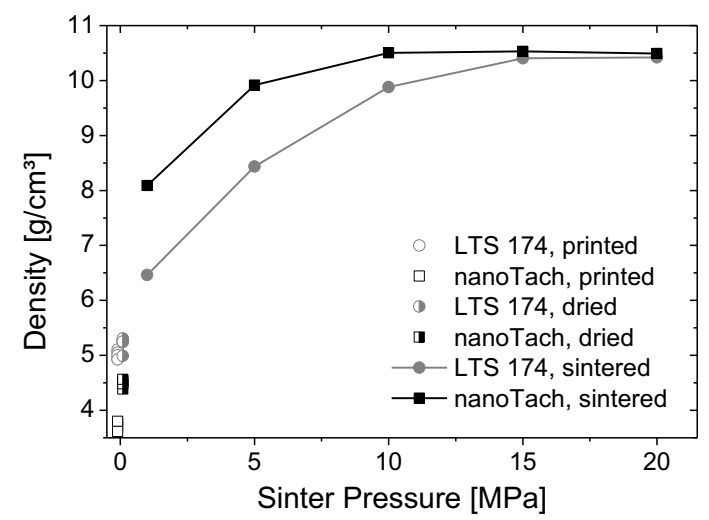

Fig. 5. Density of silver sintered layers depending on sinter pressure for paste LTS 174 and nanoTach.

The nano scale paste shows little higher density values at the same sinter pressure, which is assumed to be due to the higher surface energy of the smaller silver grains.

After passive temperature cycling, results can be understood best, if we regard the maps of the delamination and Young's modulus depending on sinter pressure and number of cycles for each chip size and paste.

Cycling tests with the nanoTach paste by NBE and silicon device A with a chip size of $7.8 \times 7.8$ $x 0.31 \mathrm{~mm}^{3}$ show an increasing elastic modulus and a decreasing area of delamination with higher sinter pressures (see Fig. 6 and Fig. 7). At $1 \mathrm{MPa}$ test results are less clear because of a bigger tolerance of the pressure in the sinter press.

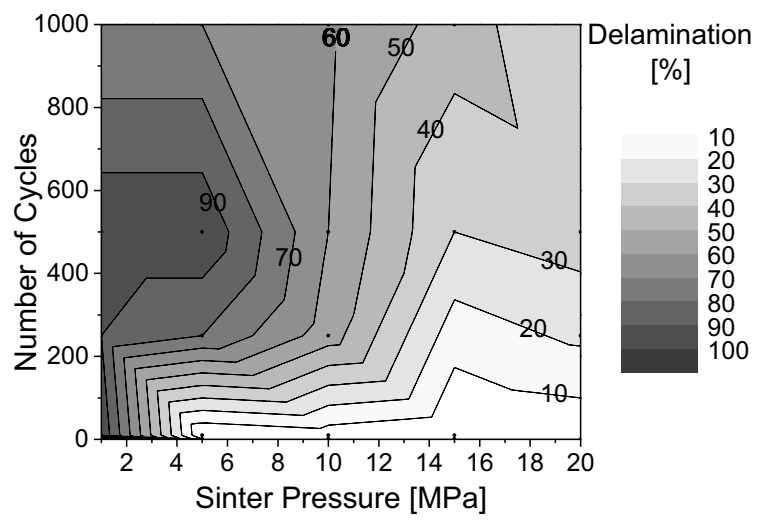

Fig. 6. Delamination versus sinter pressure and number of cycles for paste nanoTach, chip $A$.

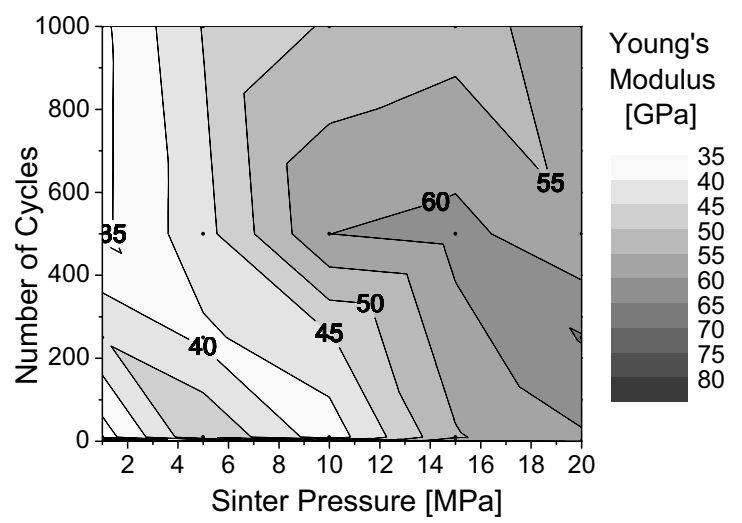

Fig. 7. Young's Modulus versus sinter pressure and number of cycles for paste nanoTach, chip $A$.

With a sintering pressure of $20 \mathrm{MPa}$ a maximum Young's modulus of $60.4 \mathrm{GPa}$ was reached for the nanoTach paste and of $54,5 \mathrm{GPa}$ for paste LTS 174 . This is comparable with values found in literature with 30 to $60 \mathrm{GPa}$ for the sintered layer and 60 to $80 \mathrm{GPa}$ for pure silver [13].

Passive temperature cycling with the nanoTach paste and chip B with $9 \times 9 \times 0.261 \mathrm{~mm}^{3}$ (Fig. 8 
and Fig. 9) almost show the same results as with the smaller chip size before.

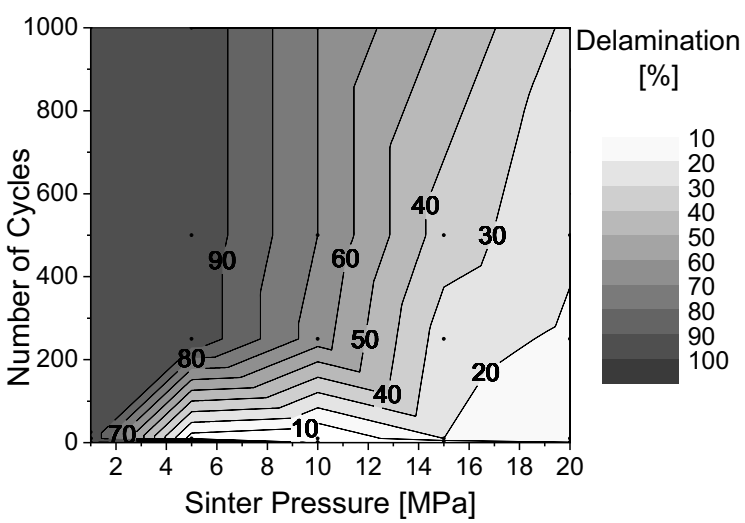

Fig. 8. Delamination versus sinter pressure and number of cycles for paste nanoTach, chip $B$.

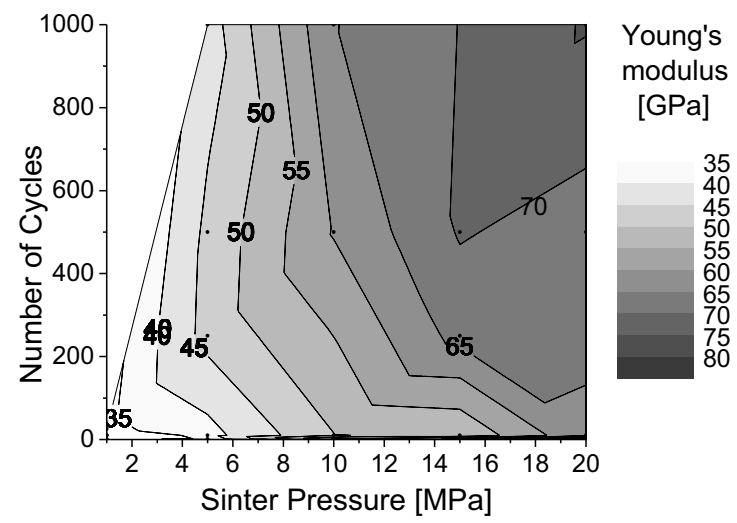

Fig. 9. Young's Modulus versus sinter pressure and number of cycles for paste nanoTach, chip $B$.

The thinner and larger IGBT devices chip $C$ with a chip size of $10.47 \times 10.44 \times 0.12 \mathrm{~mm}^{3}$ show much less delamination, but a Young's modulus comparable to the other to chip sizes, also with the nanoTach sinter paste (Fig. 10 and Fig. 11). Delamination also increases significantly with a growing number of thermal cycles, contrarily to Young's modulus.

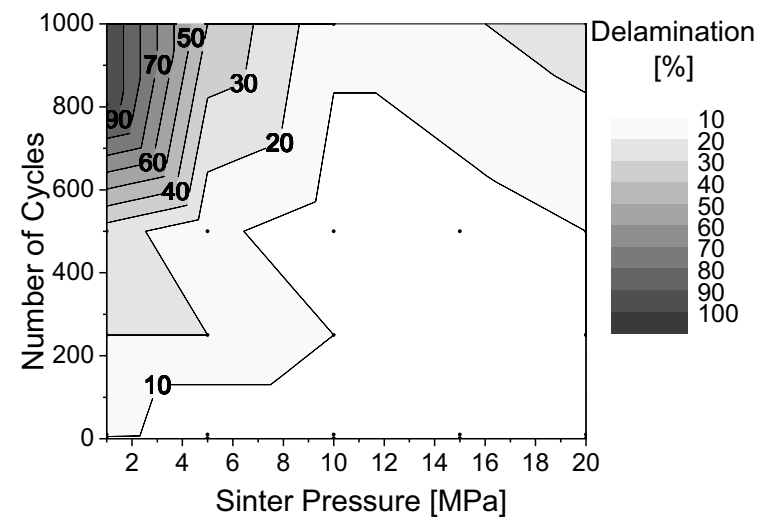

Fig. 10. Delamination versus sinter pressure and number of cycles for paste nanoTach, chip C.

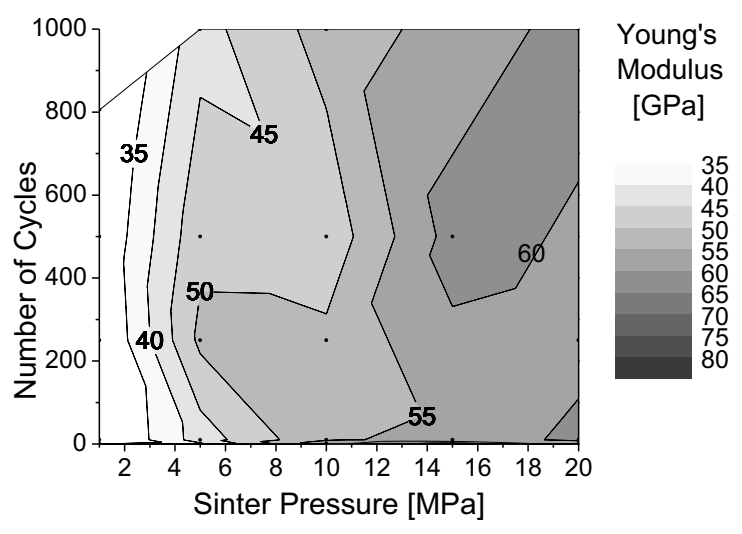

Fig. 11. Young's Modulus versus sinter pressure and number of cycles for paste nanoTach, chip C.

Passive temperature cycling with chip $C$ and paste LTS 174 reveals a similar ageing behavior to the nanoTach paste with the same device (Fig. 12 and Fig. 13). Compared to the nanoTach paste, delamination is slightly increased at the same number of cycles and sinter pressure. This fits well the assumption that larger grains in the sinter paste need a higher sinter pressure to reach the same density like shown in Fig. 5.

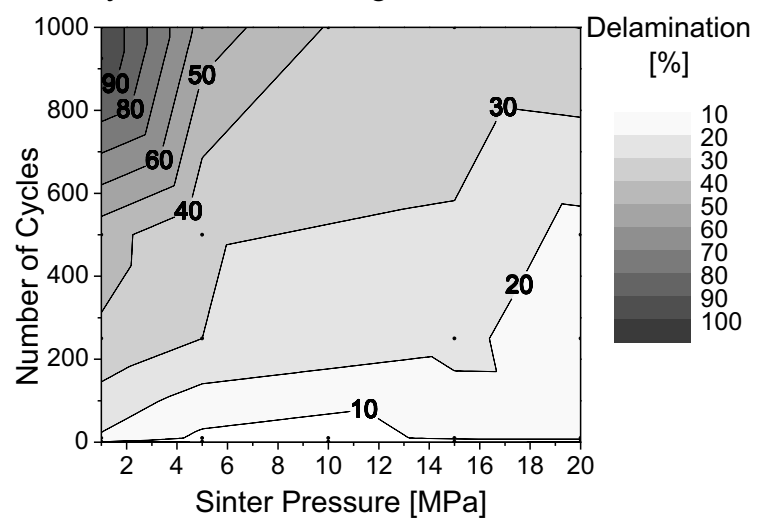

Fig. 12. Delamination versus sinter pressure and number of cycles for paste LTS 174, chip C.

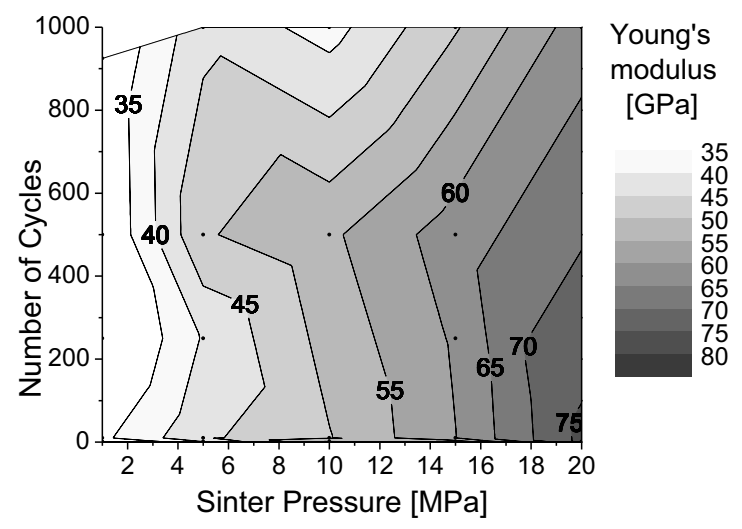

Fig. 13. Young's Modulus versus sinter pressure and number of cycles for paste LTS 174, chip C.

No relation between a progress of thermal fatigue over passive temperature cycles and 
Young's modulus can be detected. A further sintering of the silver pastes during passive temperature cycling therefore could not be found.

The sinter pressure has a great influence on the Young's modulus, independent on chip size and thermal cycling fatigue, which is shown in Fig. 14 at 500 thermal cycles:

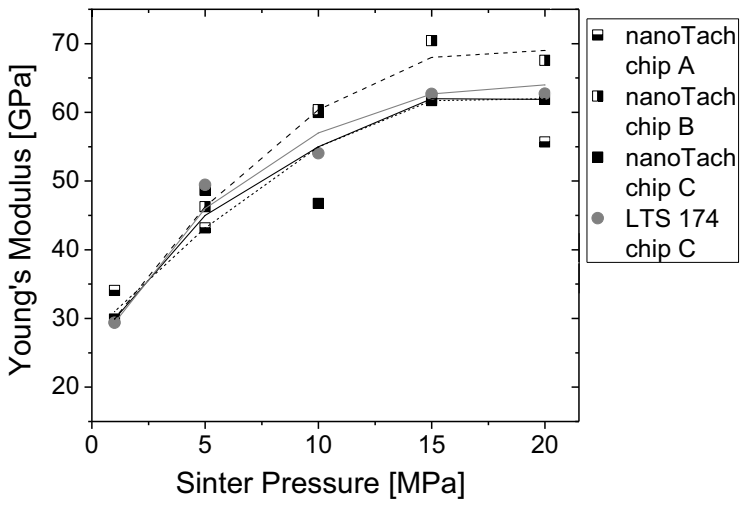

Fig. 14. Influence of sinter pressure on Young's modulus, after 500 cycles from $-5^{\circ} \mathrm{C}$ to $+175^{\circ} \mathrm{C}$

The main influences on the delamination of the sinter layer are the chip geometry and the sinter pressure (see Fig. 15). Also the delamination of the sinter layer decreases with the size of the silver particles in the paste at the same sinter pressure.

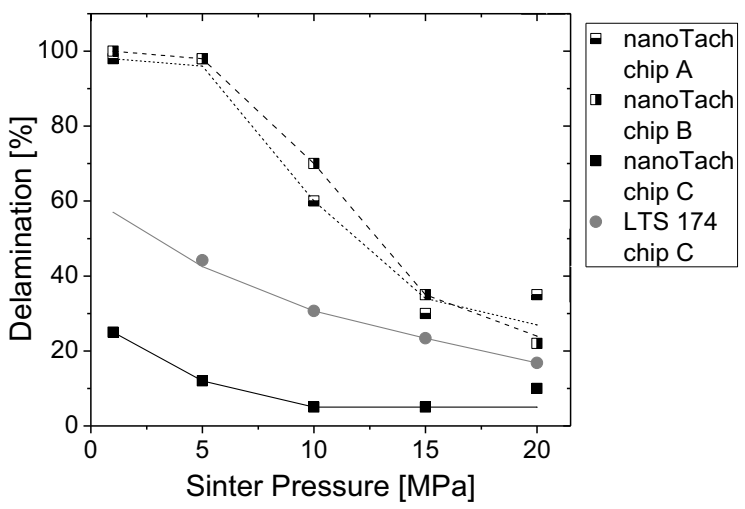

Fig. 15. Influence of sinter pressure on delamination, after 500 cycles from $-5{ }^{\circ} \mathrm{C}$ to $+175^{\circ} \mathrm{C}$

\section{Conclusions}

A maximal Young's modulus of $60.4 \mathrm{GPa}$ at a sinter pressure of $20 \mathrm{MPa}$ was measured in this work. Test results show a correlating influence of the sintering pressure on the lifetime in passive temperature cycles as well as on Young's modulus. The chip geometry and the size of the silver particles in the paste have a clear influence on the delamination during thermal cycling, but not on the elastic modulus. No dependence of the elastic modulus from proceeding thermal cycling could be detected.

\section{References}

[1] M. Knoerr, S. Kraft, A. Schletz, Reliability Assessment of Sintered Nano-Silver Die Attach for Power Semiconductors, 12th Electronics Packaging Technology Conference EPTC, 56-61 (2010); doi: 10.1109/EPTC.2010.5702605

[2] H. Schwarzbauer, Method of Securing Electronic Components to a Substrate, United States Patent 4,810, 672 (1987)

[3] H. Schwarzbauer, R. Kuhnert, Novel large area joining technique for improved power device performance, IEEE Industry Applications Society Annual Meeting, Vol. 27, 93-95 (1991); doi: 10.1109/28.67536

[4] K. S. Siow, Mechanical properties of nano-silver joints as die attach materials, Journal of Alloys and Compounds 514, 6-19 (2012); doi: 10.1016/j.jallcom.2011.10.092

[5] J. Kähler, N. Heuck, A. Wagner, A. Stranz, E. Peiner, A. Waag, Sintering of Copper Particles for Die Attach, IEEE Transactions on Components, Packaging and Manufacturing Technology, Vol. 2, Issue 10, 1587-1591 (2012); doi: 10.1109/TCPMT.2012.2201940

[6] X. Li, X. Chen, D.-J. Yu, G.-Q. Lu, Study on Adhesive Reliability of Low-Temperature Sintered High Power LED Modules, 11th Int. Conference on Electronic Packaging Techn. ICEPT, 13711376 (2010); doi: 10.1109/ICEPT.2010.5582818

[7] W. Schmitt, Novel Silver Contact Paste - Lead Free Solution for Die Attach, 6th International Conference in Integrated Power Electronic Systems CIPS, VDE Berlin, 351-356 (2010)

[8] M. Knörr, Verbinden von Leistungshalbleiterbauelementen durch Sintern von nanoskaligen Silberpartikeln, Shaker Aachen, 117-122 (2011)

[9] R. Amro, J. Lutz, J. Rudzki, R. Sittig, M. Thoben, Power Cycling at High Temperature Swings of Modules with Low Temperature Joining Technique, 18th International Symposium on Power Semiconductor Devices \& IC's, (2006); doi: 10.1109/ISPSD.2006.1666110

[10] U. Scheuermann, Reliability of Planar SKiN Interconnect Technology, 7th International Conference in Integrated Power Electronic Systems CIPS, VDE Berlin, 464-471 (2012)

[11] K. Guth, N. Oeschler, L. Böwer, R. Speckels, G. Strotmann, N. Heuck, S. Krasel, A. Ciliox, New assembly and interconnect technologies for power modules, 7th International Conference in Integrated Power Electronic Systems CIPS, VDE Berlin, 380-384 (2012)

[12] A. C. Fischer-Cripps, Nanoindentation, Springer New York, 2+31 (2011)

[13] C. Mertens, Die NiedertemperaturVerbindungstechnik der Leistungselektronik, VDI Düsseldorf, 94-95 (2004) 